\title{
Impact of the Brazilian Family Health Strategy on child oral health-related quality of life: a cohort study
}

\section{Renita Baldo MORAES(a) \\ Camila Silveira SFREDDO(b)}

Thiago Machado ARDENGHI(c)

(a) Universidade de Santa Cruz do Sul - UNISC, School of Dentistry, Department of Health Sciences, Santa Cruz do Sul, RS, Brazil.

(b) Universidade Franciscana - UFN, School of Dentistry, Santa Maria, RS, Brazil.

(c) Universidade Federal de Santa Maria UFSM, Faculty of Dentistry, Department of Stomatology, Santa Maria, RS, Brazil.

Declaration of Interests: The authors certify that they have no commercial or associative interest that represents a conflict of interest in connection with the manuscript.

Corresponding Author:

Thiago Machado Ardenghi

E-mail: thiardenghi@hotmail.com

https://doi.org/10.1590/1807-3107bor-2021.vol35.0093

Submitted: July 3, 2020

Accepted for publication: March 3, 2021

Last revision: March 18, 2021

\begin{abstract}
Most of the Brazilian population is covered by the Family Health Strategy (FHS), however no longitudinal study has assessed the impact of the FHS on child oral health-related quality of life (OHRQoL). The objective of the study was to evaluate the longitudinal impact of the FHS on the OHRQoL. This study followed up 459 children aged 2 to 5 years for 2 years. OHRQoL was assessed by the Brazilian version of the Early Childhood Oral Health Impact Scale (ECOHIS) at baseline (April to November 2016) and follow-up (April to December 2018). Children's parents answered a questionnaire regarding sociodemographic information, FHS service, and dental service. Participants were clinically examined for dental caries. Multilevel Poisson regression was used to assess the associations between FHS variables at baseline and overall/domain-specific of the ECOHIS scores over time. A total of 365 children were reassessed for OHRQoL (follow-up rate: 79.5\%). The absence of FHS coverage from the child's first year of age was associated with higher scores in the family function domain [rate ratio $(R R)=2.42$; 95\% confidence interval (CI) 1.28-4.58)]. Home visits by the FHS team members were associated with higher psychological domain scores $(\mathrm{RR}=1.60 ; 95 \% \mathrm{CI} 1.01-2.57)$. Children not covered by the FHS since the first year of age reported worse OHRQoL over time. This fact highlights the importance of an integrated health approach to promote children's health.
\end{abstract}

Keywords: Child; Health Services; Oral Health; Primary Health Care; Quality of Life.

\section{Introduction}

The National Unified Health System (SUS) has improved health and quality of life through strategies for expanding and improving primary health care in Brazil. ${ }^{1}$ In this context, the Family Health Strategy (FHS) is the main approach for the reorganization of Brazilian primary health care. $^{2}$ This community-based strategy is guided on the principles of health promotion, disease prevention, and treatment of common health conditions with an emphasis on family and community health. ${ }^{2}$ In 2000, the oral health team was included in the FHS as a measure to reorganize oral health care. However, approximately $30 \%$ of the FHS 
centers does not have an oral health team available. ${ }^{3}$ The coverage of the FHS is approximately $63 \%$ of the Brazilian population. ${ }^{3}$

Previous studies have demonstrated the positive impact of the FHS on general health indicators of different populations, including children. The implementation of the FHS has been associated with a reduction in infant mortality rates and health inequalities, with a greater effect in cities with a lower Human Development Index. ${ }^{4,5}$ In addition, there was a reduction in malnutrition rates in children aged under 5 years ${ }^{6}$ and in the number of hospitalizations for communicable diseases, such as gastroenteritis in 1-year-old children. ${ }^{7}$

There are few studies assessing the impact of the FHS on clinical and self-reported oral health outcomes. A cross-sectional study showed that children aged 0-14 years regularly monitored by the FHS team attended dental services more frequently when compared to whose that did not have a regular source of health care. ${ }^{8}$ Similarly, the oral health services in the FHS promoted dental visits for children aged 3-5 years. ${ }^{9}$ However, other studies showed that there was no difference in the use of services by preschoolers ${ }^{10}$ and adults. ${ }^{11,12}$

The functional, social, and psychological dimensions of oral health are an integral part of the general health and well-being of the population. ${ }^{13}$ Therefore, strategies for reorienting services should assess the impact of the FHS on clinical and subjective measures. Thus, oral health-related quality of life (OHRQoL) as a subjective measure can be used to assess the effectiveness of policies in health services. ${ }^{13}$ OHRQoL is a multidimensional construct regarding the impact of oral diseases and disorders on aspects of daily life, and their impact on experience and perception of the individual's life. ${ }^{14}$

Although the majority of the Brazilian population has FHS coverage, to the best of our knowledge there is no longitudinal study assessing the impact of the FHS on OHRQoL in children. The assessment of the FHS impact on self-perceived measures, such as OHRQoL, is essential for evaluation of the effect of oral health strategies and planning of public health policies with prioritization of services. Therefore, the aim of this study was to evaluate the longitudinal impact of the FHS on the OHRQoL of preschool children. We hypothesized that preschool children enrolled in the FHS would have better OHRQoL.

\section{Methodology}

\section{Study design and sample}

This cohort study included 2-5-year-old children from Santa Cruz do Sul, a southern city in Brazil. Santa Cruz do Sul has an estimated population of 118,374 inhabitants, which include 2,944 children aged 0 to 5 years and $59 \%$ of these were registered in statal kindergartens..$^{15}$ The city is characterized by the longevity of the population (Human Development Index $=0.77)^{15}$ and it has approximately $57 \%$ of FHS coverage with 21 FHS teams. ${ }^{3}$ The FHS team is composed of a multidisciplinary team that has at least a physician, a nurse, a nursing assistant, and a community health worker. ${ }^{16}$

The baseline of this study took place between April and November 2016, and the follow-up occurred between April and December 2018. At baseline, a two-stage sampling was adopted. The primary sampling units were all 18 public preschools in the urban area of the city. The secondary sampling units were all 2-5-year-old children who were enrolled in the 18 preschools. All preschool children who participated in the initial evaluation were invited to participate in a further assessment.

The sample size of this study was estimated based on the prevalence of use of dental services in the exposed (children with poor OHRQoL) and unexposed (children with high OHRQoL) groups of 26.3 and $15 \%,{ }^{17}$ respectively, a $95 \%$ confidence interval (CI), a statistical power of $80 \%$, and adding a $15 \%$ to account for the non-response rate. Thus, the minimum sample size was set at 463 children at baseline. Children with any degree of mental or cognitive disability were excluded from the sample. A total of 477 children were invited to participate; of these, 12 were denied permission by their guardians and four were excluded from the sample for other reasons (participation rate: $96.3 \%$ ). Thus, the final sample comprised 459 preschool children at baseline. 
The study protocol was approved by the Committee of Ethics in Research of the Universidade de Santa Cruz do Sul (CAAE 44105715.1.0000.5343, 2016 e 86026218.2.0000.5343, 2018). All parents signed a free and informed consent form in the two phases of the study.

\section{Data collection}

Data were collected through questionnaires and clinical oral examinations using standardized procedures in the two assessments of the study.

OHRQoL was assessed using the Brazilian version of Child Early Childhood Oral Health Impact Scale $(\text { ECOHIS })^{18}$ applied at school through face-to-face interviews by trained examiners. If the parents could not attend the school, the interview was conducted by telephone. The ECOHIS questionnaire contains 13 items, divided into child impact section (child symptoms, function, psychological, and self-image/ social interaction domains) and a family impact section (parental distress and family function domains). Answers were recorded through a rating scale from 0 to 5: 0-"never", 1-“hardly ever", 2-"occasionally", 3-"often", 4-“very often", and 5-“do not know". The mean ECOHIS scores were calculated for each domain and for the total scale as a sum of the response codes after recoding all the "do not know" responses as missing. Total scores ranged from 0 to 52, with higher values indicating poorer OHRQoL of children and their families. ${ }^{18}$

Children' sociodemographic, health service, and dental service characteristics were collected from parents through a questionnaire and included age, sex, skin color, maternal educational level, household income, participation in a social welfare program of the Brazilian government (the "Bolsa Família Program"), FHS variables, and use of dental service. The questionnaire was piloted in a sample of 20 parents; no adjustments in the questions were necessary after testing the instrument. These parents were not part of the final sample.

The skin color was defined as "white", "black", "brown (pardos)", "indigenous", and "yellow" according to the Brazilian criteria. ${ }^{15}$ These variables were categorized as "white" and "non-white." The maternal educational level was assessed through years of formal schooling in Brazil, and it was categorized as $<9$ years or 9 years or more of schooling (complete primary education). Monthly household income was obtained from all sources in Brazilian reals ( $R$ \$), which is the official currency of Brazil (US\$ 1.0 is equivalent to $\mathrm{R} \$ 5.0$ approximately, as of January 2021). The Bolsa Família benefit was self-reported by the caregivers as "yes" or "no". The Bolsa Família Program was created by the Brazilian government in 2003 and it aimes to assist extremely poor families with conditional cash transfer. ${ }^{19}$ The extreme poverty classification is considered for poor families with children, teenagers up to the age of 17 , and pregnant and lactating women. ${ }^{19}$

The FHS variables were FHS coverage from the child's first year of age and home visit from the FHS team. FHS coverage was collected by the family register in the FHS from official municipal records and verified according to the child's date of birth. After that, the variable was categorized into "yes" or "no". Home visit from the FHS team was measured through the question: "Do you receive visits at your home from community health workers or another member of the FHS team?" Answers were categorized in "yes" or "no". Access to the public dental service was verified according to the presence of a health unit (FHS or traditional) with a dentist near the child's address. The information was obtained from official records, and it was categorized in "yes" or "no". Traditional health units were considered those that mainly offer curative treatment. The child's reason for visiting a dentist was measured by the following question: "What was the reason for your child's last visit to the dentist?" Answers were categorized in "check-up/routine" or "treatment".

Full-mouth clinical examination was performed using standardized international criteria for oral health surveys. ${ }^{20}$ Untreated caries was measured by the non-zero decay component in the decayed, missing, and filled teeth index $(\mathrm{dmft}) \cdot{ }^{20} \mathrm{Three}$ examiners were trained and calibrated to assess dental caries in a room, with natural light, using CPI probes ("ball point") and dental mirrors. The process included theoretical activities with discussion regarding the diagnostic criteria of dental caries and the examination of 17 children. These children were not part of the 
final sample. At baseline, inter- and intra-examiner reproducibility (Kappa statistics) for $\mathrm{dmft}$ ranged from 0.85 to 0.94 .

\section{Statistical analysis}

Descriptive data analysis was carried out using Stata (StataCorp. 2014. Stata Statistical Software: Release 14.1. StataCorp LP, College Station, TX). The predictors were considered the FHS variables (FHS coverage from the child's first year of age and home visits by a FHS team) at baseline. The outcome variable was the longitudinal changes in OHRQoL. The variable was obtained by each domain and overall ECOHIS scores at baseline and follow-up.

Multilevel Poisson regression models were used to estimate the association between independent variables at baseline and longitudinal changes in OHRQoL. In the multilevel structure, the domain and overall ECOHIS scores measured overtime (level 1) were nested in children (level 2). The multilevel model used the scheme of fixed effect with random intercept. The results are presented as rate ratio (RR) and its respective $95 \% \mathrm{CI}$. In this approach, variables with a $\mathrm{p}$-value $<0.20$ in the unadjusted model were included in the adjusted model. The variables remained in the adjusted model only if they showed a p-value $<0.05$ after adjustment. The quality of the fit of the model was evaluated using the deviance ( $-2 \log$ likelihood). Significant changes in the fitting of the models were assessed using the likelihood ratio test.

\section{Results}

From 459 children aged 2-5 years examined at baseline, we re-examined 365 children at the 2-year follow-up (follow-up rate of 79.5\%). The flowchart of participants and reasons for dropouts are presented in Figure.

Table 1 presents sociodemographic, health service, and oral health characteristics of the participants. The prevalence of girls was 50.1 and $49.6 \%$ at baseline and follow-up, respectively. The participants' skin color was predominantly white in the two assessments. The mean age of children was 3.6 years [standard deviation $(\mathrm{SD})=1.1]$ and 5.5 years $(\mathrm{SD}=1.0)$ at baseline and follow-up, respectively. Most children were not registered in the FHS since the first year of age $(62.7 \%)$ and they did not receive home visits from the FHS team (61.4\%). However, $58 \%$ of them had dental service at the public health unit where they were registered. The main reason for visiting a dentist was check-up/routine, and the mean of untreated caries was $1.0(\mathrm{SD}=2.1)$ and $1.3(\mathrm{SD}=2.2)$ at baseline and follow-up, respectively. There were no

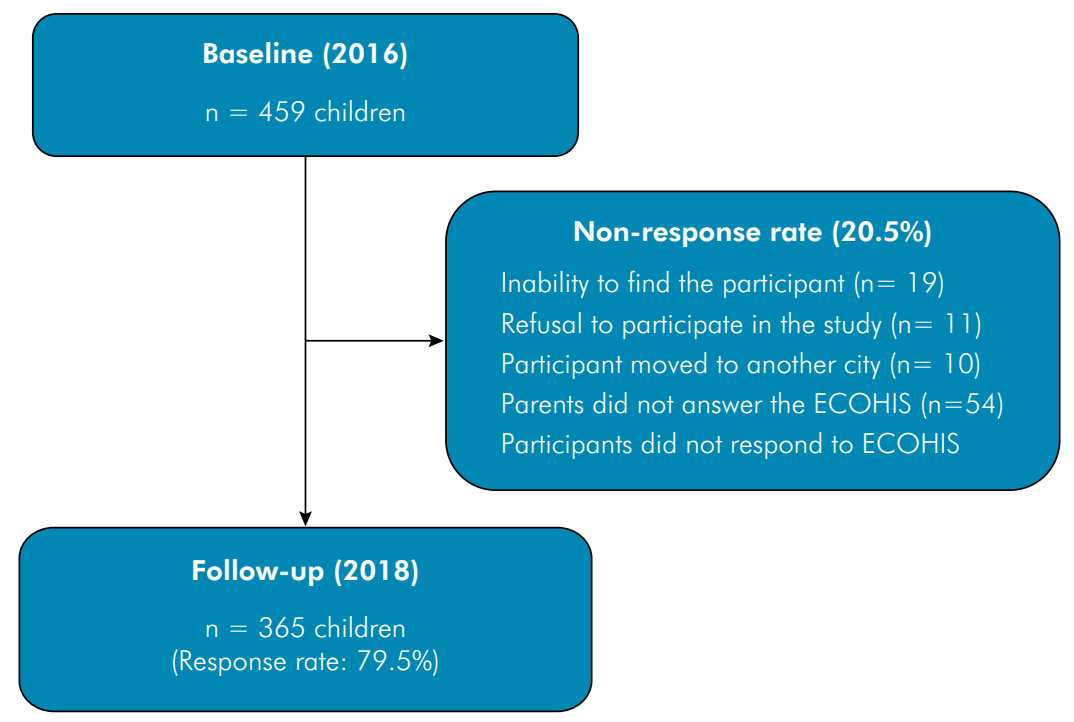

Figure. Flowchart of participants. 
Table 1. Sociodemographic, health service, and oral health characteristics of the participants and dropouts.

\begin{tabular}{|c|c|c|c|c|}
\hline \multirow{2}{*}{ Variables } & Baseline ( $\mathrm{T} 1)$ & Follow-up (T2) & Dropouts* & \multirow{2}{*}{$\mathrm{p}$-value } \\
\hline & $(n=459)$ & $(n=365)$ & $(n=94)$ & \\
\hline \multicolumn{5}{|l|}{ Sociodemographic characteristics } \\
\hline $\operatorname{Sex}[n(\%)]$ & 459 & 365 & 94 & \multirow{3}{*}{0.66} \\
\hline Girls & $230(50.1)$ & $181(49.6)$ & $49(52.1)$ & \\
\hline Boys & $229(49.9)$ & $184(50.4)$ & $45(47.9)$ & \\
\hline Age (years) [mean (SD)] & $3.6(1.1)$ & $5.5(1.0)$ & $3.7(1.1)$ & 0.17 \\
\hline Skin color [n (\%)] & 446 & 365 & 81 & \multirow{3}{*}{0.10} \\
\hline White & $354(79.4)$ & $295(80.8)$ & 59 (72.8) & \\
\hline Non-white & $92(20.6)$ & $70(19.2)$ & $22(27.2)$ & \\
\hline Maternal education [n (\%)] & 444 & 363 & 81 & \multirow{3}{*}{0.01} \\
\hline$\geq 9$ years & $324(73.0)$ & $276(76.0)$ & 48 (59.3) & \\
\hline$<9$ years & $120(27.0)$ & $87(24.0)$ & $33(40.7)$ & \\
\hline $\begin{array}{l}\text { Household income in } \mathrm{R} \$ \\
\text { [mean (SD)] }\end{array}$ & $2,188.99(1,484.8)$ & $\begin{array}{l}2,868.10 \\
(2,301.9)\end{array}$ & $\begin{array}{l}1,873.22 \\
(1,128.9)\end{array}$ & 0.04 \\
\hline Bolsa Família benefit [n (\%)] & 444 & 348 & 80 & \\
\hline No & $359(80.9)$ & $312(90.0)$ & $62(77.5)$ & 0.40 \\
\hline Yes & $85(19.1)$ & $36(10.0)$ & $18(22.5)$ & \\
\hline \multicolumn{5}{|l|}{ Health service characteristics } \\
\hline FHS since first year of age $[n(\%)]$ & 451 & 349 & 86 & \multirow{3}{*}{$<0.01$} \\
\hline Yes & $168(37.3)$ & $120(32.3)$ & $46(53.5)$ & \\
\hline No & $283(62.7)$ & $229(67.7)$ & $40(46.5)$ & \\
\hline Home visit by the FHS team [n (\%)] & 446 & 361 & 81 & \multirow{3}{*}{0.66} \\
\hline No & $274(61.4)$ & $212(58.7)$ & $48(59.3)$ & \\
\hline Yes & $172(38.6)$ & $149(41.3)$ & $33(40.7)$ & \\
\hline \multicolumn{5}{|l|}{ Oral health characteristics } \\
\hline Public dental service [n (\%)] & 452 & 363 & 87 & \multirow{3}{*}{0.40} \\
\hline Yes & $263(58.2)$ & $296(81.5)$ & $54(62.1)$ & \\
\hline No & $189(41,8)$ & $67(18.5)$ & 33 (37.9) & \\
\hline Reason for visiting a dentist [n (\%)] & 246 & 274 & 53 & \multirow{3}{*}{0.17} \\
\hline Check-up/routine & $159(64.6)$ & $158(57.7)$ & $30(66.6)$ & \\
\hline Treatment & $87(35.4)$ & $116(42.3)$ & $23(43.4)$ & \\
\hline Untreated dental caries [mean (SD)] & $1.0(2.1)$ & $1.3(2.2)$ & $1.5(2,6)$ & 0.02 \\
\hline
\end{tabular}

"Difference between participants followed up and dropouts. Chi-square test for categorical variables and Mann-Whitney test for continuous variables. T1: baseline; T2: Follow-up; SD: standard deviation; R $\$$ : Real (US\$1.0 is equivalent to R $\$ 5.0$ approximately); FHS: Family Health Strategy.

statistical differences between the participants and dropouts (Chi square test) regarding sex $(p=0.66)$, skin color $(\mathrm{p}=0.10)$, Bolsa Família benefit $(\mathrm{p}=0.40)$, home visit $(p=0.66)$, dental service $(p=0.40)$, reasons to visiting a dentist $(\mathrm{p}=0.17)$, and age $(\mathrm{p}=0.17$, Mann-Whitney test).

Descriptive distribution of overall and domainspecific ECOHIS are summarized in Table 2. The overall ECOHIS score ranged from 0 to 44 [mean $=2.6$ $(\mathrm{SD}=4.2)]$ and 0 to 36 [mean $=2.9(\mathrm{SD}=4.5)]$ at baseline and follow-up, respectively. At baseline, scores in the child symptoms and parental distress domains had the largest variations. At follow-up, the floor and ceiling effect was observed for all ECOHIS in almost all domains, except for child function domain. There was no difference between 
Table 2. Descriptive distribution of overall and domain-specific ECOHIS scores at baseline and 2-year follow-up.

\begin{tabular}{|c|c|c|c|c|c|c|c|c|}
\hline \multirow{3}{*}{ Variables } & \multicolumn{4}{|c|}{ Baseline ( $\mathrm{T} 1)$} & \multicolumn{4}{|c|}{ Follow-up (T2) } \\
\hline & \multirow{2}{*}{$\begin{array}{c}\text { Number of } \\
\text { items }\end{array}$} & \multirow{2}{*}{$\begin{array}{c}\text { Mean (SD) } \\
\text { ECOHIS } \\
\text { Scores }\end{array}$} & \multirow{2}{*}{$\begin{array}{c}\text { Possible } \\
\text { range }\end{array}$} & \multirow{2}{*}{$\begin{array}{c}\text { Observed } \\
\text { range }\end{array}$} & \multirow{2}{*}{$\begin{array}{c}\text { Number of } \\
\text { items }\end{array}$} & \multirow{2}{*}{$\begin{array}{c}\text { Mean (SD) } \\
\text { ECOHIS } \\
\text { Scores }\end{array}$} & \multirow{2}{*}{$\begin{array}{c}\text { Possible } \\
\text { range }\end{array}$} & \multirow{2}{*}{$\begin{array}{c}\text { Observed } \\
\text { range }\end{array}$} \\
\hline & & & & & & & & \\
\hline Overall ECOHIS & 13 & $2.6(4.2)$ & $0-52$ & $0-44$ & 13 & $2.9(4.5)$ & $0-52$ & $0-36$ \\
\hline \multicolumn{9}{|l|}{ Child impact section } \\
\hline Symptoms & 1 & $0.5(0.9)$ & $0-4$ & $0-4$ & 1 & $0.6(0.9)$ & $0-4$ & $0-4$ \\
\hline Functional & 4 & $0.6(1.4)$ & $0-16$ & $0-14$ & 4 & $0.7(1.4)$ & $0-16$ & $0-11$ \\
\hline Psychological & 2 & $0.6(1.1)$ & $0-8$ & $0-6$ & 2 & $0.4(1.0)$ & $0-8$ & $0-8$ \\
\hline Self-image/social interaction & 2 & $0.1(0.6)$ & $0-8$ & $0-7$ & 2 & $0.2(0.9)$ & $0-8$ & $0-8$ \\
\hline \multicolumn{9}{|l|}{ Family impact section } \\
\hline Parental distress & 2 & $0.6(1.4)$ & $0-8$ & $0-8$ & 2 & $0.7(1.6)$ & $0-8$ & $0-8$ \\
\hline Family function & 2 & $0.2(0.7)$ & $0-8$ & $0-7$ & 2 & $0.2(0.8)$ & $0-8$ & $0-8$ \\
\hline
\end{tabular}

SD: standard deviation.

participants and dropouts regarding overall ECOHIS $(\mathrm{p}=0.33)$ (Mann-Whitney test).

FHS variables were associated with domain-specific ECOHIS scores in the unadjusted analysis (Table 3). Thus, children not covered by FHS since the first year of age had higher scores in the family function domain $(\mathrm{p}<0.05)$ compared to their counterparts. In addition, those who received home visits from the FHS team also had the highest psychological domain scores $(p<0.05)$. The absence of public dental service access were statistically associated with higher overall and domain-specific ECOHIS scores $(p<0.05)$ (Table 3).

The adjusted multilevel Poisson regression model is shown in Table 4. In the analysis by domains, children not covered by the FHS since the first year of age reported worse OHRQoL than their counterparts, with higher scores on the family function domain $(R R=2.42 ; 95 \% C I 1.28-4.58)$. Home visits was associated with higher psychological domain scores $(\mathrm{RR}=1.60 ; 95 \% \mathrm{CI} 1.01-2.57)$. Sociodemographic factors were also associated with OHRQoL: the overall ECOHIS scores were higher for older children and those who received the "Bolsa Família" benefit. Older children also scored higher on symptoms, function, social interaction, and parent distress domains. Receiving the "Bolsa Família" benefit, in addition to the overall score, was also positively associated with higher scores in function and social interaction domains. Children whose mothers had not completed primary education had higher scores on the symptom domain. Moreover, non-white children had a higher score on the parent distress domain. This study also identified that oral health conditions were associated with OHRQoL: higher overall and domain-specific ECOHIS scores were observed in children that did not have access to public dental service, who visited a dentist for treatment, and presented untreated dental caries.

\section{Discussion}

This study evaluated the longitudinal impact of the FHS on children's OHRQoL. Our findings demonstrated that children not covered by the FHS since the first year of life had a negative impact on the family function domain, that is, the children's families presented impact on financial resources and on parents' professional performance. However, home visits from the FHS team were associated with worse children' OHRQoL.

To the best of our knowledge, this is the first study that assessed the longitudinal impact of the FHS on children's OHRQoL. The negative impact on family function domain may be related to the absence of an integrated care promoted by FHS coverage from the child's first year of age. One of the principles of the FHS is an interdisciplinary and integral approach that recognizes individual needs, with an emphasis 
Table 3. Unadjusted association between independent variables and overall and domain-specific ECOHIS scores at baseline (T1) and 2-year follow-up (T2), determined using multilevel Poisson regression.

\begin{tabular}{|c|c|c|c|c|c|c|c|}
\hline \multirow{3}{*}{ Variables } & \multicolumn{4}{|c|}{ Child section } & \multicolumn{2}{|c|}{ Family section } & \multirow{3}{*}{$\begin{array}{l}\text { Overall ECOHIS } \\
\text { RR }(95 \% \mathrm{CI})\end{array}$} \\
\hline & Symptoms & Function & Psychological & $\begin{array}{c}\text { Self-image/ } \\
\text { social } \\
\text { interaction }\end{array}$ & $\begin{array}{l}\text { Parent } \\
\text { distress }\end{array}$ & $\begin{array}{l}\text { Family } \\
\text { function }\end{array}$ & \\
\hline & RR (95\% Cl) & RR (95\% Cl) & RR $(95 \% \mathrm{CI})$ & $\operatorname{RR}(95 \% \mathrm{Cl})$ & $\operatorname{RR}(95 \% \mathrm{Cl})$ & $\operatorname{RR}(95 \% \mathrm{CI})$ & \\
\hline \multicolumn{8}{|l|}{ Sociodemographic characteristics } \\
\hline Sex & $p=0.25$ & $p=0.22$ & $p=0.77$ & $p=0.92$ & $p=0.89$ & $p=0.14$ & $p=0.65$ \\
\hline Girls & 1 & 1 & 1 & 1 & 1 & 1 & 1 \\
\hline Boys & $\begin{array}{c}1.16 \\
(0.89-1.51)\end{array}$ & $\begin{array}{c}1.26 \\
(0.86-1.83)\end{array}$ & $\begin{array}{c}1.05 \\
(0.74-1.49)\end{array}$ & $\begin{array}{c}0.95 \\
(0.39-2.28)\end{array}$ & $\begin{array}{c}0.96 \\
(0.57-1.61)\end{array}$ & $\begin{array}{c}1.53 \\
(0.86-2.75)\end{array}$ & $\begin{array}{c}1.06 \\
(0.82-1.34)\end{array}$ \\
\hline \multirow[t]{2}{*}{ Age } & $p<0.01$ & $p=0.02$ & $p=0.34$ & $p<0.01$ & $p=0.02$ & $p=0.07$ & $p<0.01$ \\
\hline & $\begin{array}{c}1.21 \\
(1.07-1.37)\end{array}$ & $\begin{array}{c}1.23 \\
(1.03-1.47)\end{array}$ & $\begin{array}{c}0.92 \\
(0.78-1.08)\end{array}$ & $\begin{array}{c}2.22 \\
(1.40-3.51)\end{array}$ & $\begin{array}{c}1.34 \\
(1.05-1.72)\end{array}$ & $\begin{array}{c}1.29 \\
(0.98-1.70)\end{array}$ & $\begin{array}{c}1.17 \\
(1.05-1.32)\end{array}$ \\
\hline Skin color & $p=0.11$ & $p=0.01$ & $p=0.86$ & $p=0.11$ & $p<0.01$ & $p=0.53$ & $p=0.09$ \\
\hline White & 1 & 1 & 1 & 1 & 1 & 1 & 1 \\
\hline Non-white & $\begin{array}{c}1.28 \\
(0.94-1.75)\end{array}$ & $\begin{array}{c}1.75 \\
(1.12-2.73)\end{array}$ & $\begin{array}{c}0.96 \\
(0.61-1.49)\end{array}$ & $\begin{array}{c}2.28 \\
(0.82-6.33)\end{array}$ & $\begin{array}{c}2.23 \\
(1.22-4.07)\end{array}$ & $\begin{array}{c}0.78 \\
(0.37-1.66)\end{array}$ & $\begin{array}{c}1.28 \\
(0.96-1.73)\end{array}$ \\
\hline Maternal education & $p=0.01$ & $p=0.03$ & $p=0.23$ & $p=0.43$ & $p=0.27$ & $p=0.82$ & $p=0.06$ \\
\hline 9 years & 1 & 1 & 1 & 1 & 1 & 1 & 1 \\
\hline$<9$ years & $\begin{array}{c}1.43 \\
(1.08-1.89)\end{array}$ & $\begin{array}{c}1.58 \\
(1.04-2.39)\end{array}$ & $\begin{array}{c}1.27 \\
(0.86-1.87)\end{array}$ & $\begin{array}{c}1.47 \\
(0.56-3.84)\end{array}$ & $\begin{array}{c}1.37 \\
(0.77-2.44)\end{array}$ & $\begin{array}{c}0.92 \\
(0.47-1.79)\end{array}$ & $\begin{array}{c}1.30 \\
(0.99-1.70)\end{array}$ \\
\hline & $p=0.73$ & $p=0.06$ & $p=0.02$ & $p=0.05$ & $p=0.50$ & $p=0.73$ & $p=0.21$ \\
\hline Household income & $\begin{array}{c}1.00 \\
(0.99-1.00)\end{array}$ & $\begin{array}{c}0.99 \\
(0.99-1.00)\end{array}$ & $\begin{array}{c}0.99 \\
(0.99-1.00)\end{array}$ & $\begin{array}{c}0.99 \\
(0.99-1.00)\end{array}$ & $\begin{array}{c}0.99 \\
(0.99-1.00\end{array}$ & $\begin{array}{c}0.99 \\
(0.99-1.00)\end{array}$ & $\begin{array}{c}0.99 \\
(0.99-0.00)\end{array}$ \\
\hline Bolsa Família benefit & $p=0.04$ & $p<0.01$ & $p<0.01$ & $p=0.03$ & $p=0.15$ & $p=0.83$ & $p=0.02$ \\
\hline No & 1 & 1 & 1 & 1 & 1 & 1 & 1 \\
\hline Yes & $\begin{array}{c}1.38 \\
(1.01-1.89)\end{array}$ & $\begin{array}{c}2.02 \\
(1.30-3.14)\end{array}$ & $\begin{array}{c}1.74 \\
(1.15-2.63)\end{array}$ & $\begin{array}{c}3.05 \\
(1.09-8.49)\end{array}$ & $\begin{array}{c}1.59 \\
(0.84-3.00)\end{array}$ & $\begin{array}{c}0.92 \\
(0.43-1.94)\end{array}$ & $\begin{array}{c}1.42 \\
(1.05-1.92)\end{array}$ \\
\hline \multicolumn{8}{|l|}{ Health service characteristics } \\
\hline FHS since first year of age & $p=0.64$ & $p=0.57$ & $p=0.16$ & $p=0.42$ & $p=0.62$ & $p=0.04$ & $P=0.99$ \\
\hline Yes & 1 & 1 & 1 & 1 & 1 & 1 & 1 \\
\hline No & $\begin{array}{c}0.93 \\
(0.71-1.22)\end{array}$ & $\begin{array}{c}0.89 \\
(0.60-1.31)\end{array}$ & $\begin{array}{c}0.77 \\
(0.54-1.10)\end{array}$ & $\begin{array}{c}0.69 \\
(0.28-1.68)\end{array}$ & $\begin{array}{c}1.14 \\
(0.66-1.96)\end{array}$ & $\begin{array}{c}1.92 \\
(1.02-3.60)\end{array}$ & $\begin{array}{c}0.99 \\
(0.77-1.28)\end{array}$ \\
\hline Home visit by the FHS team & $p=0.58$ & $p=0.13$ & $p=0.04$ & $p=0.88$ & $p=0.51$ & $p=0.07$ & $p=0.54$ \\
\hline No & 1 & 1 & 1 & 1 & 1 & 1 & 1 \\
\hline Yes & $\begin{array}{c}1.07 \\
(0.82-1.40)\end{array}$ & $\begin{array}{c}1.34 \\
(0.91-1.97)\end{array}$ & $\begin{array}{c}1.44 \\
(1.01-2.05)\end{array}$ & $\begin{array}{c}1.07 \\
(0.43-2.61)\end{array}$ & $\begin{array}{c}1.19 \\
(0.70-2.02)\end{array}$ & $\begin{array}{c}0.56 \\
(0.30-1.03)\end{array}$ & $\begin{array}{c}1.08 \\
(0.84-1.39)\end{array}$ \\
\hline \multicolumn{8}{|l|}{ Oral health characteristics } \\
\hline Public dental service & $p=0.27$ & $p=0.03$ & $p=0.02$ & $p=0.03$ & $p=0.33$ & $p=0.24$ & $p=0.01$ \\
\hline Yes & 1 & 1 & 1 & 1 & 1 & 1 & 1 \\
\hline No & $\begin{array}{c}1.15 \\
(0.89-1.50)\end{array}$ & $\begin{array}{c}1.52 \\
(1.04-2.22)\end{array}$ & $\begin{array}{c}1.54 \\
(1.08-2.18)\end{array}$ & $\begin{array}{c}2.58 \\
(1.07-6.19)\end{array}$ & $\begin{array}{c}1.29 \\
(0.76-2.18)\end{array}$ & $\begin{array}{c}1.41 \\
(0.79-2.51)\end{array}$ & $\begin{array}{c}1.38 \\
(1.08-1.76)\end{array}$ \\
\hline Reason of visiting a dentist & $\mathrm{p}<0.01$ & $p<0.01$ & $p<0.01$ & $p<0.01$ & $p<0.01$ & $p<0.01$ & $p<0.01$ \\
\hline Check-up/routine & 1 & 1 & 1 & 1 & 1 & 1 & 1 \\
\hline Treatment & $\begin{array}{c}2.28 \\
(1.69-3.07)\end{array}$ & $\begin{array}{c}2.75 \\
(1.78-4.23)\end{array}$ & $\begin{array}{c}2.31 \\
(1.45-3.66)\end{array}$ & $\begin{array}{c}5.52 \\
(1.73-17.6)\end{array}$ & $\begin{array}{c}3.50 \\
(1.92-6.37)\end{array}$ & $\begin{array}{c}2.58 \\
(1.44-4.61)\end{array}$ & $\begin{array}{c}2.41 \\
(1.82-3.19)\end{array}$ \\
\hline & $p<0.01$ & $p<0.01$ & $p<0.01$ & $p=0.02$ & $p<0.01$ & $p=0.01$ & $p<0.01$ \\
\hline Untreated dental caries & $\begin{array}{c}1.15 \\
(1.09-1.21)\end{array}$ & $\begin{array}{c}1.18 \\
(1.0-1.27)\end{array}$ & $\begin{array}{c}1.11 \\
(1.03-1.19)\end{array}$ & $\begin{array}{c}1.25 \\
(1.041 .49)\end{array}$ & $\begin{array}{c}1.47 \\
(1.34-1.62)\end{array}$ & $\begin{array}{c}1.16 \\
(1.03-1.31)\end{array}$ & $\begin{array}{c}1.20 \\
(1.15-1.27)\end{array}$ \\
\hline
\end{tabular}

RR: rate ratio; C195\%: 95\% confidence interval; FHS: Family Health Strategy. 
Impact of the Brazilian Family Health Strategy on child oral health-related quality of life: a cohort study

Table 4. Adjusted association between independent variables and overall and domain-specific ECOHIS scores at baseline (T1) and 2-year follow-up (T2), determined using multilevel Poisson regression.

\begin{tabular}{|c|c|c|c|c|c|c|c|}
\hline \multirow{3}{*}{ Variables } & \multicolumn{4}{|c|}{ Child section } & \multicolumn{2}{|c|}{ Family section } & Overall ECOHIS \\
\hline & Symptoms & Function & Psychological & $\begin{array}{c}\text { Self-image/ } \\
\text { social interaction }\end{array}$ & $\begin{array}{l}\text { Parent } \\
\text { distress }\end{array}$ & $\begin{array}{l}\text { Family } \\
\text { function }\end{array}$ & \multirow[t]{2}{*}{ RR $(95 \% \mathrm{Cl})$} \\
\hline & $\mathrm{RR}^{\circ}(95 \% \mathrm{Cl})$ & $\operatorname{RR}(95 \% \mathrm{Cl})$ & RR $(95 \% \mathrm{Cl})$ & RR $(95 \% \mathrm{Cl})$ & RR $(95 \% \mathrm{CI})$ & RR $(95 \% \mathrm{CI})$ & \\
\hline
\end{tabular}

Sociodemographic characteristics

Sex

Girls

Boys

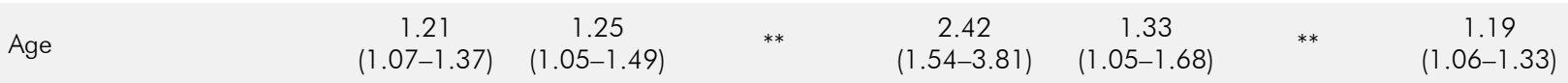

Skin color

White

Non-white

2.16

(1.23-3.80)

Maternal education

$\begin{array}{lc}9 \text { years } & 1 \\ <9 \text { years } & 1.41 \\ & (1.08-1.87)\end{array}$

Household income

Bolsa Família benefit

** ** **

\begin{tabular}{|c|c|c|c|}
\hline No & ** & $\begin{array}{c}1.98 \\
(1.29-3.06)\end{array}$ & $\begin{array}{c}3.12 \\
(1.18-8.27\end{array}$ \\
\hline
\end{tabular}

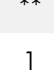

3.12

40

.04-188

Health service characteristics

FHS since first year of age

Yes

**

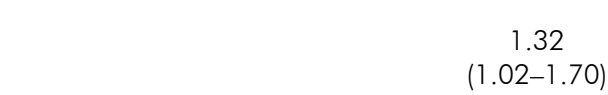

No

Home visit by the FHS team

No

Yes
**

1.60

$(1.01-2.57)$
Oral health characteristics

Public dental service

\begin{tabular}{|c|c|c|c|}
\hline Yes & $* *$ & 1 & 1 \\
\hline No & & $\begin{array}{c}1.67 \\
(1.05-2.67)\end{array}$ & $\begin{array}{c}2.83 \\
(1.23-6.54)\end{array}$ \\
\hline
\end{tabular}

Reason of visiting a dentist
Check-up/routine

Treatment

Untreated dental caries
1.75

(1.29-2.41)

1.08

(1.03-1.14) (1.02-1.20)
$1.83 \quad 2.08$

(1.18-2.87) (1.31-3.30)

1.11

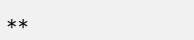

(1.05-1.47)
2.42

(1.28-4.58)

${ }^{* *}$ Non-significant. RR: rate ratio; Cl95\%: 95\% confidence interval; FHS: Family Health Strategy 
on general well-being and quality of life. ${ }^{21}$ Families whose children have not been covered by the FHS since the first year of age may have used other models of health service, prioritizing only the treatment of diseases. In this context, traditional health units prioritize curative treatment based on a biomedical model of health care with an emphasis on disease. On the other hand, children assisted by the FHS since the first year of age received a health service based on individual and cultural needs based on the health promotion approach. ${ }^{22}$

Our findings also demonstrated that children who received home visits had worse OHRQoL with high psychological limitation domain scores. The selection of families that received home visits from the FHS team takes into account vulnerability and epidemiological risk for diaseases. ${ }^{21}$ Families in social vulnerability generally have a worse socioeconomic position and, consequently, the worst levels of health. ${ }^{23}$ Thus, it is possible that the families most visited by the FHS team are those with the worst oral health conditions, leading to a negative impact on OHRQoL.

Sociodemographic factors were also associated with reported OHRQoL. Age was associated with higher impact on children' OHRQoL in accordance with another study. ${ }^{22}$ The longer exposure of the teeth in the oral cavity of older children can result in increased caries experience, and consequently generates more pain and discomfort, impacting OHRQoL. ${ }^{24,25}$ In addition, non-white children whose mothers have not completed primary education, and those with the Bolsa Familia benefit had a negative impact on OHRQoL. These sociodemographic characteristics can measure the socioeconomic position of the children's family. ${ }^{23}$ Therefore, they can reflect a set of differential exposures of economic and non-economic resources, such as the emotional and social meanings of inequalities for children's life, which can influence self-esteem and coping, with negative impact on OHRQoL. ${ }^{23}$ In addition, the worst socioeconomic position reflects lack of material resources, such as food and health services. ${ }^{23}$

The absence of access to public dental service was associated with higher overall and domainspecific (psychological and social interaction) ECOHIS scores. In addition, children who visited a dentist for treatment had worst OHRQoL. These findings are in accordance with previous studies. ${ }^{26,27}$ The access to dental services can contribute to reducing oral health inequities, prioritizing preventive actions, and consequently, health promotion. On the other hand, the difficulty in accessing health services can result in using the service only in situations of pain and need for treatment. Dental treatment in children is usually due to oral diseases, such as dental caries, which can cause toothache, impacting daily activities, such as talking, eating, toothbrushing, and sleeping pattern. ${ }^{28}$ Pain experiences can affect social interactions, physical and psychosocial well-being, and quality of life. ${ }^{28}$

Previous studies also showed the negative impact of dental caries on OHRQoL. ${ }^{26,29}$ Children with untreated dental caries can experience pain and impaired chewing, ${ }^{27,29}$ impacting their social interactions and well-being. Additionally, parents may be more likely to feel worried or upset about their child's health and report worst OHRQoL..$^{29}$

Our study presents some limitations. The study included only children from public preschools. However, the majority of children (59\%) attended statal preschools. Moreover, participants from different socioeconomic status were selected in all neighborhoods of the city, allowing the address of the social gradient in oral health. Previous studies ${ }^{23,24}$ have also used the same approach. Another limitation is that attributes of the health units, such as work process and training of health professionals to act in health promotion actions, were not assessed. Thus, it is not possible to verify if the FHS teams were acting in accordance with the recommended guidelines for primary health care. Additionally, the nonresponse rate (approximately 20\%) could be a source of bias. However, there were no statistical differences between the participants and dropouts regarding overall ECOHIS and the majority of characteristics.

The strength of this study is the assessment of the FHS impact on oral health measures. The majority of previous studies focus on understanding the process of implementing health teams. Also, our study demonstrated the FHS impact on longitudinal changes in children's OHRQoL. The scarce resources for public health policies reinforce the importance 
of the longitudinal evaluation of the FHS and its contribution to improving the health and quality of life of the population. Patient-reported outcomes, such OHRQoL are essential to complement traditional clinical measures and plan public health policies.

\section{Conclusion}

Our study indicates that children not covered by the FHS since the first year of life have a negative impact on the family function domain of OHRQoL. This finding highlighted the importance of an integrated health approach for promoting children's well-being and tackling health inequalities.

\section{Acknowledgments}

The authors thank the children and their families, as well as the preschools and the Municipal Education Authorities from Santa Cruz do Sul, RS, Brazil.

\section{References}

1. Victora CG, Aquino EM, Leal Mc, Monteiro CA, Barros FC, Szwarcwald CL. Maternal and child health in Brazil: progress and challenges. Lancet. 2011 May;377(9780):1863-76. https://doi.org/10.1016/S0140-6736(11)60138-4

2. Paim J, Travassos C, Almeida C, Bahia L, Macinko J. The Brazilian health system: history, advances, and challenges. Lancet. 2011 May;377(9779):1778-97. https://doi.org/10.1016/S0140-6736(11)60054-8

3. Ministério da Saúde (BR). E-Gestor Atenção Básica. Cobertura da Atenção Básica 2019. Brasília, DF: Ministério da Saúde; 2019 [cited 2020 May 28]. Available from: https://egestorab.saude.gov.br/paginas/acessoPublico/relatorios/ relHistoricoCoberturaAB.xhtml

4. Aquino R, Oliveira NF, Barreto ML. Impact of the family health program on infant mortality in Brazilian municipalities. Am J Public Health. 2009 Jan;99(1):87-93. https://doi.org/10.2105/AJPH.2007.127480

5. Barreto ML, Rasella D, Machado DB, Aquino R, Lima D, Garcia LP, et al. Monitoring and evaluating progress towards Universal Health Coverage in Brazil. PLoS Med. 2014 Sep;11(9):e1001692. https://doi.org/10.1371/journal.pmed.1001692

6. Benício MH, Martins AP, Venancio SI, Barros AJ. [Estimates of the prevalence of child malnutrition in Brazilian municipalities in 2006]. Rev Saude Publica. 2013 Jun;47(3):560-70. Portuguese. https://doi.org/10.1590/S0034-8910.2013047004379

7. Pinto Junior EP, Aquino R, Medina MG, Silva MG. [Effect of the Family Health Strategy on hospitalizations for primary care sensitive conditions in infants in Bahia State, Brazil]. Cad Saude Publica. 2018 Feb;34(2):e00133816. Portuguese. https://doi.org/10.1590/0102-311x00133816

8. Baldani MH, Mendes YB, Lawder JA, Lara AP, Rodrigues MM, Antunes JL. Inequalities in dental services utilization among Brazilian low-income children: the role of individual determinants. J Public Health Dent. 2011;71(1):46-53. https://doi.org/10.1111/j.1752-7325.2010.00201.x

9. Baldani MH, Rocha JS, Fadel CB, Nascimento AC, Antunes JL, Moysés SJ. Assessing the role of appropriate primary health care on the use of dental services by Brazilian low-income preschool children. Cad Saude Publica. 2017 Nov;33(11):e00158116. https://doi.org/10.1590/0102-311x00158116 PMID:29166484

10. Rodrigues LA, Martins AM, Silveira MF, Ferreira RC, Souza JG, Silva JM, et al. [The use of dental services among preschool children: a population-based study]. Cien Saude Colet. 2014 Oct;19(10):4247-56. Portuguese. https://doi.org/10.1590/1413-812320141910.13382013

11. Rocha RA, Goes PS. [Comparison of access to Oral Health Services between areas covered and not covered by the Family Health Program in Campina Grande, Paraíba State, Brazil]. Cad Saude Publica. 2008 Dec;24(12):2871-80. Portuguese. https://doi.org/10.1590/S0102-311X2008001200016

12. Carreiro DL, Souza JG, Coutinho WL, Haikal DS, Martins AM. [Access to dental services and related factors: a home-based population study[. Cien Saude Col. 2019 Mar;24(3):1021-32. Portuguese. https://doi.org/10.1590/1413-81232018243.04272017

13. Sischo L, Broder HL. Oral health-related quality of life: what, why, how, and future implications. J Dent Res. 2011 Nov;90(11):1264-70. https://doi.org/10.1177/0022034511399918

14. Locker D, Allen F. What do measures of 'oral health-related quality of life' measure? Community Dent Oral Epidemiol. 2007 Dec;35(6):401-11. https://doi.org/10.1111/j.1600-0528.2007.00418.x

15. Instituto Brasileiro de Geografia e Estatística. Censo 2010. Brasília, DF: Instituto Brasileiro de Geografia e Estatística; 2010 [cited 2020 March 10]. Available from: http://www.ibge.gov.br/home/estatistica/populacao/ 
16. Pucca Junior GA, Gabriel M, Araujo ME, Almeida FC. Ten years of a National Oral Health Policy in Brazil: innovation, boldness, and numerous challenges. J Dent Res. 2015 Oct;94(10):1333-7. https://doi.org/10.1177/0022034515599979

17. Goettems ML, Ardenghi TM, Demarco FF, Romano AR, Torriani DD. Children's use of dental services: influence of maternal dental anxiety, attendance pattern, and perception of children's quality of life. Community Dent Oral Epidemiol. 2012 Oct;40(5):451-8. https://doi.org/10.1111/j.1600-0528.2012.00694.x

18. Tesch FC, Oliveira BH, Leão A. [Semantic equivalence of the Brazilian version of the Early Childhood Oral Health Impact Scale]. Cad Saude Public. 2008 Aug;24(8):1897-909. Portuguese. https://doi.org/10.1590/s0102-311×2008000800018

19. Silva ES, Paes NA. [Bolsa Família Programme and the reduction of child mortality in the municipalities of the Brazilian semiarid region]. Cien Saude Colet. 2019 Feb;24(2):623-30. Portuguese. https://doi.org/10.1590/1413-81232018242.04782017

20. World Health Organization. Oral health surveys: basic methods. 5th ed. Geneva: World Health Organization; 2013.

21. Ministério de Estado da Saúde (BR). Portaria N².436, de 21 de setembro de 2017. Aprova a Política Nacional de Atenção Básica, estabelecendo a revisão de diretrizes para a organização da Atenção Básica, no âmbito do Sistema Único de Saúde (SUS). Diário Oficial União, 2017 Sept 21.

22. Starfield B. Atenção primária: equilíbrio entre necessidades de saúde, serviços e tecnologia. Brasília, DF: Unesco; Ministério da Saúde; 2002.

23. Solar O, Irwin A. A conceptual framework for action on the social determinants of health. Geneva: World Health Organization; 2010. (Social determinants of health discussion, paper 2).

24. Antunes LA, Ornellas G, Fraga RS, Antunes LS. Oral health outcomes: the association of clinical and socio-dental indicators to evaluate dental caries in preschool children. Cien Saude Colet. 2018 Feb;23(2):491-500. https://doi.org/10.1590/1413-81232018232.21022015

25. Piva F, Pereira JT, Luz PB, Hugo FN, Araúio FB. Caries progression as a risk factor for increase in the negative impact on OHRQOL-a longitudinal study. Clin Oral Investig. 2018 Mar;22(2):819-28. https://doi.org/10.1007/s00784-017-2157-4

26. Knorst JK, Menegazzo GR, Emmanuelli B, Mendes FM, Ardenghi TM. Effect of neighborhood and individual social capital in early childhood on oral health-related quality of life: a 7-year cohort study. Qual Life Res. 2019 Jul;28(7):1773-82. https://doi.org/10.1007/s11136-019-02138-4

27. Åstrøm AN, Ekback G, Ordell S, Gulcan F. Changes in oral health-related quality of life (OHRQoL) related to long-term utilization of dental care among older people. Acta Odontol Scand. 2018 Nov;76(8):559-66. https://doi.org/10.1080/00016357.2018.1474249

28. Ortiz FR, Tomazoni F, Oliveira MD, Piovesan C, Mendes F, Ardenghi TM. Toothache, associated factors, and its impact on Oral Health-Related Quality of Life (OHRQoL) in preschool children. Braz Dent J. 2014 Nov-Dec;25(6):546-53. https://doi.org/10.1590/0103-6440201302439

29. Chaffee BW, Rodrigues PH, Kramer PF, Vítolo MR, Feldens CA. Oral health-related quality-of-life scores differ by socioeconomic status and caries experience. Community Dent Oral Epidemiol. 2017 Jun;45(3):216-24. https://doi.org/10.1111/cdoe.12279 